\title{
Rapid increase in lymphogranuloma venereum in men who have sex with men, United Kingdom, 2003 to September 2015
}

T Childs ${ }^{1}$, I Simms ${ }^{1}$, S Alexander ${ }^{2}$, K Eastick ${ }^{3}$, G Hughes ${ }^{1}$, N Field ${ }^{14}$

1. HIV and STI Department, Public Health England Health Protection Services, Colindale, United Kingdom

2. Sexually Transmitted Bacteria Reference Unit, Public Health England Reference Microbiology Services, Colindale, United Kingdom

3. Scottish Bacterial Sexually Transmitted Infections Reference Laboratory, Edinburgh Royal Infirmary, Edinburgh, United Kingdom

4. Department of Infection and Population Health, University College London, London, United Kingdom

Correspondence: Nigel Field (nigel.field@phe.gov.uk)

Citation style for this article:

Childs T, Simms I, Alexander S, Eastick K, Hughes G, Field N. Rapid increase in lymphogranuloma venereum in men who have sex with men, United Kingdom, 2003 to September 2015. Euro Surveill. 2015;20(48):pii=30076. DOI: http://dx.doi.org/10.2807/1560-7917.ES.2015.20.48.30076

Article submitted on 19 November 2015 / accepted on 02 December 2015 / published on 03 December 2015

United Kingdom (UK) national data show a sharp increase in diagnoses of lymphogranuloma venereum (LGV) since 2012. Most cases are in men who have sex with men (MSM) living in London, with high rates of co-infection with HIV and other sexually transmitted infections. In light of these data, and the recent finding that one quarter of LGV infections may be asymptomatic, clinicians should be vigilant in testing for LGV, including in asymptomatic HIV-positive MSM.

Laboratory diagnoses of lymphogranuloma venereum (LGV) in the United Kingdom (UK) declined between 2010 and 2012, but the most recent data show near doubling of cases since 2012 to unprecedented levels in 2014 (679 cases). This trend has continued into 2015, with 683 cases diagnosed by 30 September. In 2014, most cases were in men who have sex with men (MSM) and around three quarters were HIV-positive. Here we report national surveillance data showing trends in LGV diagnoses in the UK from 2003 to September 2015.

\section{Testing protocol and data sources}

Rectal, genital or urine samples from patients with symptoms compatible with LGV and diagnosed with Chlamydia trachomatis in England, Wales and Northern Ireland, and their sexual contacts with C. trachomatis, are submitted by local laboratories for LGV typing to the Public Health England national reference laboratory, the Sexually Transmitted Bacteria Reference Unit (STBRU) in London. Scottish samples from symptomatic patients are similarly submitted to the Scottish Bacterial Sexually Transmitted Infections Reference Laboratory (SBSTIRL) in Edinburgh. In addition, since 2007, samples from asymptomatic HIV-positive MSM diagnosed with $C$. trachomatis are also sent to SBSTIRL. During the reporting period, (January 2003 to September 2015) STBRU and SBSTIRL diagnoses accounted for all confirmed LGV cases diagnosed in the UK. Duplicates were excluded and repeat diagnoses within 42 days (used to define a single episode of care across surveillance systems in England) were counted as a single episode [1].

Additional data, including sexual behaviour and clinical information, were collected through nationally coordinated enhanced surveillance of LGV in the UK between 2004 and 2010 [2]. However, the most recent laboratory dataset lacks this enhanced information. We therefore matched laboratory reports for LGV diagnoses to the Genitourinary Medicine Clinic Activity Dataset (GUMCADv2), an anonymised patient-level electronic dataset, for all cases in England in 2014. All commissioned sexual health services in England have been mandated to return GUMCADv2 data, which include patient characteristics, other sexually transmitted infection (STI) diagnoses and services provided, since 2009 [3]. A code for LGV diagnosis was introduced in 2011 , such that most cases are now reported through GUMCADV2. LGV diagnoses in female or heterosexual male patients in GUMCADv2 were excluded from this analysis because they may represent miscoding (six cases).

\section{Trends in confirmed laboratory reports}

Between 1 January 2003 and 30 September 2015, there were 4,124 LGV diagnoses in the UK (36 from Scotland since 2011). Of these, 4,111 (99.7\%) were in men, and 242 had repeat diagnoses. LGV was first reported in the UK in 2003 (one case) and in 2004, 28 cases were reported (Figure). 
Number of cases diagnosed with lymphogranuloma venereum, per quarter, United Kingdom, 2003 to end September 2015 $(\mathrm{n}=4,124)$

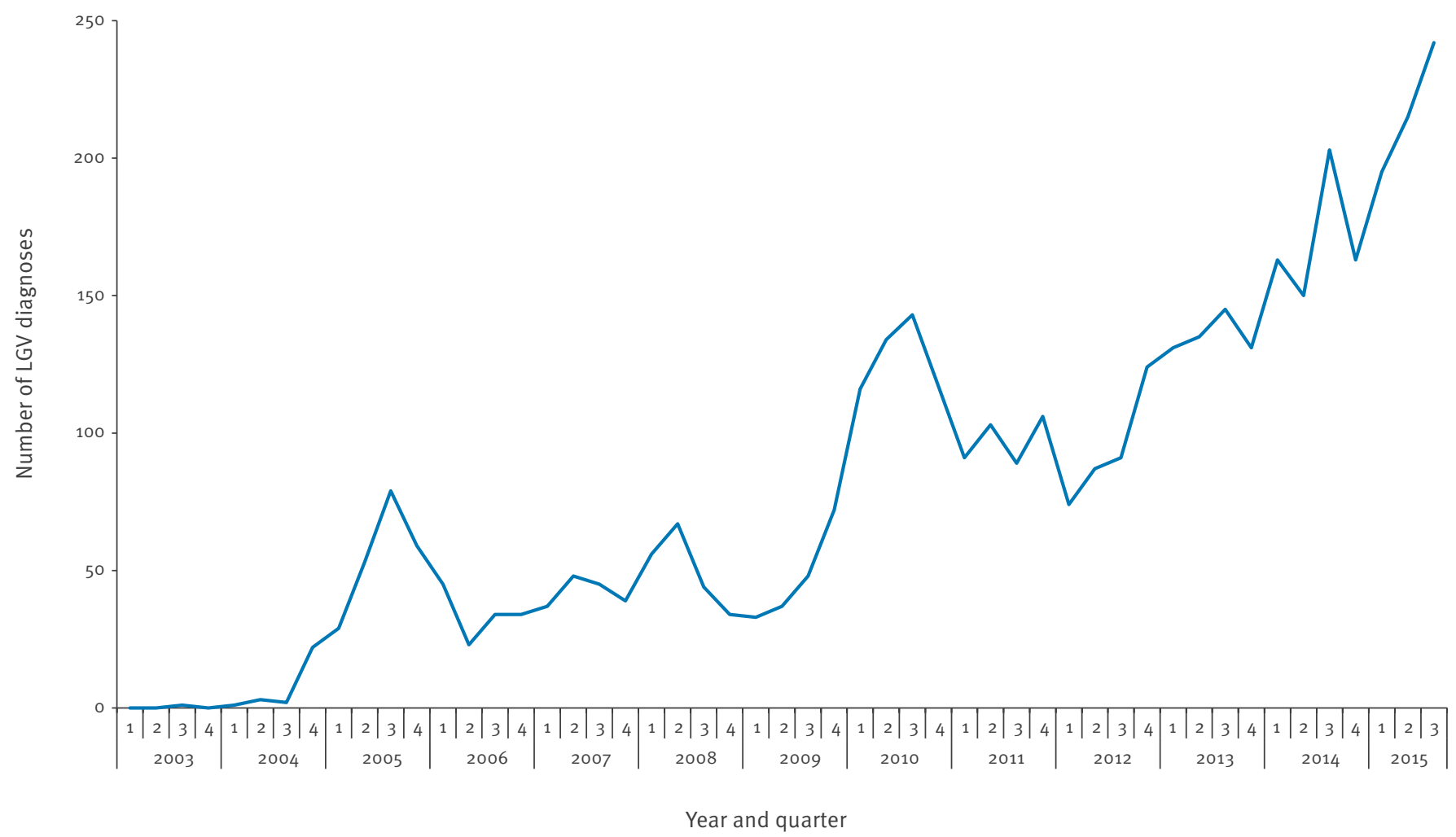

LGV: lymphogranuloma venereum.

Since 2003, the overall trend in LGV cases has been upward, with three rapid increases in 2005 (220 cases), 2010 (510 cases) and 2014 (679 cases), and intervening periods of stable or falling numbers between 2006 and 2009 (136 to 201 cases) and 2011 and 2012 (389 and 376 cases). There has been a sustained increase in diagnoses since 2012, such that diagnoses in 2014 were $81 \%$ higher than in 2012 (376 cases), and in the first quarter of 2015 , there were 195 LGV diagnoses compared with 163 diagnoses in the same time period in 2014 .

\section{Case characteristics among clinical reports}

In 2014, 11,468 diagnoses of C. trachomatis among MSM and 633 LGV cases were reported to GUMCADV2. Of the LGV cases, 434 (69\%) could be matched to the laboratory dataset. Among the matched MSM cases, the median (IQR) age at LGV diagnosis was 37 (range: 31-44) years, and most were white (320, 74\%), born in the UK $(239,55 \%)$ and living in London $(323,74 \%)$. Most cases were HIV-positive $(321,74 \%)$ and of these, nearly all were diagnosed with HIV before or at the same time as their LGV diagnosis (313, 98\%). Many patients were diagnosed with another STI or blood borne virus infection at any time during $2014(272,63 \%)$, including gonorrhoea $(219,50 \%)$, syphilis $(76,18 \%)$ and hepatitis C (13, 3\%) (Table).

\section{Background}

LGV is a STI caused by the invasive $L$ serovars of $C$. trachomatis. An outbreak among MSM was first reported in the Netherlands in 2003 and LGV outbreaks in MSM have since been reported by many high-income countries, with HIV co-infection being a common feature [4-8]. Most reported infections are rectal, and the most common presentation is proctitis, associated with rectal pain, discharge and bleeding $[5,9]$. Some cases of LGV, particularly in the beginning of the outbreak, were misdiagnosed as Crohn's disease $[10,11]$. The complications of incorrectly treated or untreated LGV are serious, particularly for immunocompromised individuals, including genital ulcers, fistulas, rectal strictures and genital elephantiasis. LGV acquisition is associated with concurrent STI infections and reported behaviours such as condomless anal intercourse, fisting and the use of sex toys [2].

\section{Discussion}

Since 2003, LGV diagnoses have increased over a twelve-year period, with a steep rise since 2012, to reach unprecedented levels in 2015, suggesting high levels of ongoing transmission. Infection remains concentrated in white MSM living in London, many with HIV co-infection and other STIS. 
TABLE

Characteristics of MSM patients from STBRU laboratory reports matched to GUMCADv2 dataset, United Kingdom, $2014(\mathrm{n}=434)$

\begin{tabular}{|c|c|c|}
\hline Characteristics & Number & Percentage \\
\hline Total number of patients ${ }^{\mathrm{a}}$ & 434 & 100 \\
\hline \multicolumn{3}{|l|}{$\mathrm{Age}^{\mathrm{b}}$} \\
\hline Median (IQR) & 37 & $31-44$ \\
\hline $16-24$ & 20 & 5 \\
\hline $25-34$ & 146 & 34 \\
\hline $35-44$ & 165 & 38 \\
\hline $45-54$ & 86 & 20 \\
\hline $55-64$ & 12 & 3 \\
\hline$\geq 65$ & 2 & $\ll 1$ \\
\hline \multicolumn{3}{|c|}{ Other STI or blood borne virus infection diagnosed in $2014^{c}$} \\
\hline Gonorrhoea & 219 & 50 \\
\hline Syphilis & 76 & 18 \\
\hline Genital herpes & 36 & 8 \\
\hline Genital warts (Condyloma acuminata) & 26 & 6 \\
\hline Hepatitis C & 13 & 3 \\
\hline \multicolumn{3}{|l|}{ HIV status } \\
\hline Positive & 321 & 74 \\
\hline Negative or unknown & 113 & 26 \\
\hline \multicolumn{3}{|c|}{ Proximity of HIV diagnosis to LGV diagnosis ${ }^{b}$} \\
\hline HIV>3 months before LGV & 234 & 73 \\
\hline HIV o-3 months before LGV & 30 & 9 \\
\hline Same date & 49 & 15 \\
\hline HIV o-3 months after LGV & 5 & 2 \\
\hline HIV>3 months after LGV & 3 & 1 \\
\hline \multicolumn{3}{|l|}{ Area of patient residence } \\
\hline London & 323 & 74 \\
\hline Manchester & 18 & 4 \\
\hline Brighton & 7 & 2 \\
\hline Birmingham & 7 & 2 \\
\hline Other & 79 & 18 \\
\hline \multicolumn{3}{|l|}{ Country of birth ${ }^{b}$} \\
\hline United Kingdom & 239 & 57 \\
\hline Outside United Kingdom & 177 & 43 \\
\hline \multicolumn{3}{|l|}{ Ethnicity ${ }^{b}$} \\
\hline White & 320 & 77 \\
\hline Asian & 16 & 4 \\
\hline Black & 20 & 5 \\
\hline Mixed & 28 & 7 \\
\hline Other & 29 & 7 \\
\hline
\end{tabular}

GUMCADv2: Genitourinary Medicine Clinic Activity Dataset; IQR: interquartile range; LGV: lymphogranuloma venereum; MSM: men who have sex with men; STBRU: sexually transmitted bacteria reference unit; STI: sexually transmitted infection.

a Of 677 positive LGV test results in 2014,440 were successfully matched to GUMCADv2. Six of these were excluded because they were recorded as female or heterosexual in GUMCADv2, leaving 434 matched patients.

${ }^{b}$ For patients with information available.

c All other STI diagnoses were new except for 14 recurrent cases of genital herpes and 17 recurrent cases of genital warts.
The strength of this study lies in the unique national dataset of laboratory confirmed LGV diagnoses, which we linked to clinical data for the most recent complete year. During the study period, LGV testing was only recommended for symptomatic patients and LGV contacts. However, a large multicentre case-finding study in the UK found that $27 \%$ of LGV infections were detected in patients without rectal symptoms, suggesting that infections might be missed $[12,13]$. Patients might also be treated presumptively without LGV testing or never seek care, leading to further underestimation of LGV cases in the population. Other external factors might have influenced requests for LGV testing and the trends observed. These include the introduction of charging laboratories for LGV diagnostic testing (April 2014) and increased awareness of LGV among clinicians and microbiologists, which might have led to increased testing. We lack data on symptoms associated with LGV infection in this surveillance dataset.

The increase in LGV diagnoses coincides with upward trends in other STIs and sexually transmissible enteric infections among MSM, such as gonorrhoea, infectious syphilis, verotoxin-producing Escherichia coli and Shigella [14-17]. Contributory factors might include sexual networks with high rates of partner change facilitated by social media networking sites and chemsex, and we know that HIV-positive MSM who engage in HIV sero-adaptive behaviours and have condomless sex with other HIV-positive men remain at particularly high risk [15-17]. Our data suggest a need for a strengthened public health response to raise awareness of LGV among clinicians and patients. Social media might offer a means of rapid, low-cost dissemination of public health messages, with an additional benefit of facilitating user interaction [18].

There are also important implications for clinical management and microbiologists, including the need for robust partner notification, testing and treatment, and testing of HIV-positive MSM with asymptomatic C. trachomatis infection for LGV [19]. LGV treatment requires an extended course of antibiotics over non-LGV C. trachomatis, such that some patients may unnecessarily receive multiple courses of antibiotics; this risks introducing selection pressure for antimicrobial resistance [20]. Clinicians should maintain a high index of suspicion for LGV in HIV-positive MSM with rectal symptoms, and consider treating presumptively for LGV according to national guidelines $[21,22]$.

\section{Acknowledgements}

We would like to thank members of the LGV Incident Group, past and present, and all clinicians who reported to enhanced LGV surveillance. We also thank all members, past and present, of the Public Health England Sexually Transmitted Bacteria Reference Unit who have been involved in processing specimens, and of the HIV and STI department involved in the processing and analysis of enhanced LGV surveillance data. Past and present members of the LGV Incident Group: Barry Evans, Kevin Fenton, Heather Jebbari, (HIV \& 
STI Department, Public Health England Colindale); Patrick French (Mortimer Market Centre, London); Gillian Dean, Andy Parkhouse, Zoe Warwick and Iain Reeves (Claude Nicol Centre, Brighton); Anne Sullivan, Sanjeeva Pallawela, Gary Seaton, James Hardie and Naa Torshie Annan (Chelsea and Westminster Hospital, London); Neil Irvine (Health Protection Agency Northern Ireland); John White (Guys and St Thomas's Hospital Trust, London); Neil Macdonald (Imperial College London, London); Andy Winter (HIV and Genitourinary Medicine, Sandyford Initiative, Glasgow); Lesley Wallace (Health Protection Scotland); Daniel Thomas and Gemma Northey (National Public Health Service for Wales); Alexander Macmillan and Dan Clutterbuck (Edinburgh Royal Infirmary); Ben Tunstall, Marc Thompson and Rod Watson (Terrence Higgins Trust); Helen Maguire, Paul Crook and Josh Forde (Public Health England London Epidemiology Unit); Lorraine Hickey (HSE, Republic of Ireland).

\section{Conflict of interest}

None declared.

\section{Authors' contributions}

TC, IS, GH, and NF drafted the manuscript. TC undertook data analysis assisted by SA and KE. All authors contributed to data interpretation and revised the manuscript.

\section{References}

1. Hughes G, Nichols T, Peters L, Bell G, Leong G, Kinghorn G. Repeat infection with gonorrhoea in Sheffield, UK: predictable and preventable?Sex Transm Infect. 2013;89(1):38-44. DOI: 10.1136/sextrans-2012-050495 PMID: 22717472

2. LGV Incident Group,Hughes G, Alexander S, Simms I, Conti $\mathrm{S}$, Ward $\mathrm{H}$, Powers C, et al. . Lymphogranuloma venereum diagnoses among men who have sex with men in the U.K.: interpreting a cross-sectional study using an epidemic phase specific framework.Sex Transm Infect. 2013;89(7):542-7. DOI: 10.1136/sextrans-2013-051051 PMID: 23851189

3. Savage EJ, Mohammed H, Leong G, Duffell S, Hughes G. Improving surveillance of sexually transmitted infections using mandatory electronic clinical reporting: the genitourinary medicine clinic activity dataset, England, 2009 to 2013. Euro Surveill. 2014;19(48):20981.

4. Nieuwenhuis RF, Ossewaarde JM, Götz HM, Dees J, Thio HB, Thomeer MG, et al. Resurgence of lymphogranuloma venereum in Western Europe: an outbreak of Chlamydia trachomatis serovar 12 proctitis in The Netherlands among men who have sex with men. Clin Infect Dis. 2004;39(7):996-1003. DOI: 10.1086/423966 PMID: 15472852

5. Ward H, Martin I, Macdonald N, Alexander S, Simms I, Fenton $\mathrm{K}$, et al. Lymphogranuloma venereum in the United kingdom. Clin Infect Dis. 2007;44(1):26-32. DOI: 10.1086/509922 PMID: 17143811

6. Savage EJ, van de Laar MJ, Gallay A, van der Sande M, Hamouda 0 , Sasse $A$, et al. Lymphogranuloma venereum in Europe, 2003-2008. Euro Surveill. 2009 Dec 3;14(48). pii: 19428.

7. Tinmouth J, Rachlis A, Wesson T, Hsieh E. Lymphogranuloma venereum in North America: case reports and an update for gastroenterologists. Clinical gastroenterology and hepatology: the official clinical practice journal of the American Gastroenterological Association. 2006;4(4):469-73.

8. Simms I, Ward H, Martin I, Alexander S, Ison C. Lymphogranuloma venereum in Australia.Sex Health. 2006;3(3):131-3. DOI: 10.1071/SHo6039 PMID: 17044217

9. UK LGV Incident Group,Jebbari H, Alexander S, Ward H, Evans B, Solomou M, Thornton A, et al. . Update on lymphogranuloma venereum in the United Kingdom.Sex Transm Infect. 2007;83(4):324-6. DOI: 10.1136/sti.2007.026740 PMID: 17591663

10. Patel S, Hay P. Lymphogranuloma venereum and HIV infection: misdiagnosed as Crohn's disease. BMJ case reports. 2010.

11. Forrester B, Pawade J, Horner P. The potential role of serology in diagnosing chronic lymphogranuloma venereum (LGV): a case of LGV mimicking Crohn's disease.Sex Transm
Infect. 2006;82(2):139-40, discussion 141. DOI: 10.1136/ sti.2005.016667 PMID: 16581740

12. Saxon C, Hughes G, Ison C, for the UK LGV Case-Finding Group. Asymptomatic Lymphogranuloma Venereum Infection in Men who Have Sex with Men, United Kingdom.Emerg Infect Dis. Forthcoming 2016.

13. Koper NE, van der Sande MA, Gotz HM, Koedijk FD. Lymphogranuloma venereum among men who have sex with men in the Netherlands: regional differences in testing rates lead to underestimation of the incidence, 2006-2012. Euro Surveill. 2013 Aug 22;18(34). pii: 20561.

14. Jebbari H, Simms I, Conti S, Marongiu A, Hughes G, Ward H, et al. Variations in the epidemiology of primary, secondary and early latent syphilis, England and Wales: 1999 to 2008. Sex Transm Infect. 2011;87(3):191-8. DOI: 10.1136/sti.2009.040139 PMID: 21262786

15. Hughes G, Field N. The epidemiology of sexually transmitted infections in the UK: impact of behavior, services and interventions.Future Microbiol. 2015;10(1):35-51. DOI: $10.2217 /$ fmb.14.110 PMID: 25598336

16. Simms I, Gilbart VL, Byrne L, Jenkins C, Adak GK, Hughes G, et al. Identification of verocytotoxin-producing Escherichia coli O117: $\mathrm{H} 7$ in men who have sex with men, England, November 2013 to August 2014. Euro Surveill. 2014 Oct 30;19(43). pii: 20946.

17. Simms I, Field N, Jenkins C, Childs T, Gilbart VL, Dallman TJ, et al. Intensified shigellosis epidemic associated with sexual transmission in men who have sex with men--Shigella flexneri and S. Sonnei in England, 2004 to end of February 2015. Euro Surveill. 2015 Apr 16;20(15). pii: 21097.

18. Thackeray R, Neiger BL, Smith AK, Van Wagenen SB. Adoption and use of social media among public health departments.BMC Public Health. 2012;12(1):242. DOI: 10.1186/1471-2458-12-242 PMID: 22449137

19. Nwokolo NC, Dragovic B, Patel S, Tong CW, Barker G, Radcliffe K. 2015 UK national guideline for the management of infection with Chlamydia trachomatis. Int J STD AIDS. 2015. DOI: 10.1177/0956462415615443 PMID: 26538553

20. Costelloe C, Metcalfe C, Lovering A, Mant D, Hay AD. Effect of antibiotic prescribing in primary care on antimicrobial resistance in individual patients: systematic review and metaanalysis.BMJ. 2010;340(may18 2):c2096. DOI: 10.1136/bmj. C2096 PMID: 20483949

21. Mohrmann G, Noah C, Sabranski M, Sahly H, Stellbrink HJ. Ongoing epidemic of lymphogranuloma venereum in HIVpositive men who have sex with men: how symptoms should guide treatment.J Int AIDS Soc. 2014;17(4) Suppl 3;19657.PMID: 25394161

22. British Association for Sexual Health and HIV,White J, O'Farrell N, Daniels D. 2013 UK National Guideline for the management of lymphogranuloma venereum: Clinical Effectiveness Group of the British Association for Sexual Health and HIV (CEG/BASHH) Guideline development group.Int J STD AIDS. 2013;24(8):593601. DOI: 10.1177/0956462413482811 PMID: 23970591 